\title{
A contribuição da Universidade de Vassouras à comunidade através do Centro de Equoterapia
}

\author{
The University of Vassouras's contribution to the community via the Equine Therapy Center \\ Marilia Gouvêa dos Reis ${ }^{\dagger^{*}}$, Willian Ferreira de Azevedo
}

Como citar esse artigo. dos Reis, M.G.; de Azevedo, W.F.; da Silva, R.B. A contribuição da Universidade de Vassouras à comunidade através do Centro de Equoterapia. Revista Mosaico. 2019 Jul/Dez; 10 (2): SUPLEMENTO $02-10$

\begin{abstract}
Resumo
O presente artigo propôs verificar a contribuição do Centro de Equoterapia da Universidade de Vassouras, RJ, à comunidade. Equoterapia é uma metodologia terapêutica e educacional que utiliza o cavalo de forma multidisciplinar, nas áreas de Educação, Saúde e Equitação, buscando o desenvolvimento biopsicossocial de indivíduos com diversas psicopatologias.O objetivo principal é apresentar o que é equoterapia, os benefícios gerados por essa modalidade de tratamento na reabilitação psicossocial de praticantes com problemas de saúde mental, as patologias trabalhadas, nível de satisfação dos pais ou responsáveis dos praticantes, o número de praticantes atendidos, idade, sexo e relatar a história do Centro de Equoterapia de Vassouras. A metodologia utilizada foi revisão bibliográfica, pesquisa documental, através dos prontuários dos arquivos do Centro de Equoterapia e análise de conteúdo das entrevistas semiestruturadas com profissionais que tenham trabalhado no Centro e também com pais ou responsáveis que participam do Projeto.
\end{abstract}

Palavras-chave: Equoterapia, Extensão, Psicologia, Saúde mental.

\begin{abstract}
The purpose of this paper is to verify the contribution of the Riding Therapy Center of the University of Vassouras, RJ, to the local community. Equinetherapy is a therapeutic and educational methodology that uses the horse in a multidisciplinary way, in the areas of Education, Health and Equitation, seeking the biopsychosocial development of individuals with various psychopathologies. The main objective of the current paper is to present what is equine therapy, the benefits of this type of treatment in psychosocial rehabilitation of practitioners with mental health problems, the pathologies dealt with, the level of satisfaction of thepractioners' parents or guardians, the number of practitioners, their age and gender, as well as report the history of Vassouras Hippotherapy Center. The methodology used was literature review, documentary research of the archives of the EquineTherapy Center and content analysis of semi-structured interviews with both professionals who work edat the Center and parents or guardians who participate in the Project.
\end{abstract}

Keywords: Equinetherapy, Extension, Psychology, Mental Health. de campo realizada no Centro de Equoterapia da Universidade de Vassouras, RJ, que tem como objetivo o levantamento de dados sobre os praticantes atendidos e a relação da Equoterapia nos tratamentos de determinadas patologias, verificando a contribuição da prática na melhora de determinados pontos da saúde mental, físico e motora dos mesmos.

A justificativa do interesse para pesquisa sobre o Centro de Equoterapia surgiu após o estudo teórico da disciplina Optativa em Equoterapia e a participação do Estágio Específico de Saúde Mental, oferecida pelo Curso de Psicologia da Universidade de Vassouras.

A temática se demonstrou relevante pelo fato de não encontrar, no Centro de Equoterapia, levantamento do quantitativo dos praticantes atendidos, as patologias mais trabalhadas, ausência de registro dos dados a respeito da história da fundação do Centro e da avaliação sobre a melhora qualitativa da saúde mental dos praticantes após o início do trabalho.

A hipótese analisada foi se a prática contribui para a reabilitação biopsicossocial dos praticantes, utilizando para construção do estudo sobre a prática da Equoterapia. A aplicação da metodologia foi de revisão bibliográfica e análise de conteúdo das entrevistas

Ademais, para a pesquisa descritiva foirealizado análise quantitativa nos prontuários dos praticantes, no período de maio a julho de 2019, aprovada pelo Comitê de Ética em Pesquisa (3.157.089). Entrevista semiestruturada com profissionais que atuam ou

Afiliação dos autores: $\uparrow$ Graduanda, Curso de Psicologia, Universidade de Vassouras, Vassouras/RJ, Brasil.

\ Graduando, Curso de Psicologia, Universidade de Vassouras, Vassouras/RJ, Brasil.

$\S$ Docente, Curso de Psicologia, Universidade de Vassouras, Vassouras/RJ, Brasil. 
já atuaram no Centro e entrevista semiestruturada com pais ou responsáveis para a verificação do nível de satisfação, onde a orientação utilizada para a interpretação das respostas foi baseada na análise de conteúdo explicitado por Bardin (2000). Foi utilizando o Termo de Consentimento Livre e Esclarecido para a validação e utilização dos dados.

\section{Equoterapia e suas dimensões}

A Associação Nacional de Equoterapia, ANDEBRASIL, (2019)foi fundada em Brasília-DF, no dia 10 de maio de 1989, com a missão de consolidar-se como referência em ensino, pesquisa, desenvolvimento e aplicação das atividades de Equoterapia no Brasil e no exterior.

De acordo com a ANDE-BRASIL(2019), a equoterapia é a utilização do cavalo como abordagem terapêutica para tratamento de pessoas portadoras de algumas patologias.

Devido a importância dessa prática terapêutica para pessoas com deficiência, através da observação dos benefícios da prática, foi publicada no Diário Oficial da União em 14 de maio de 2019 a Lei n ${ }^{\circ} 13.830$, de 13 de maio de 2019 , que dispõe sobre a prática da equoterapia:

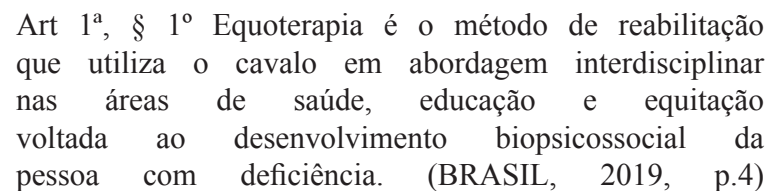

O termo Equoterapia é utilizado para todas as práticas que utilizem o cavalo como atividades equestres ou técnica de equitação, tendo como objetivo a reabilitação e/ou a educação de pessoas com diversas psicopatologias (ANDE-BRASIL, 2019).

Toda pessoa que faz tratamento terapêutico utilizando a equoterapia é chamado de praticante (ANDE-BRASIL, 2019).

Esse termo,"praticante",também é descrito na Lei $\mathrm{n}^{\circ} 13.830$, no " $\S 2^{\circ}$ entende-se como praticante de equoterapia a pessoa com deficiência que realiza atividades de equoterapia" (BRASIL, 2019, p.4).

Sendo a equoterapia uma prática que utiliza o cavalo, é importante descrever a sua relevância na área da saúde onde se visa o sentido educativo, terapêutico ou recreativo, uma vez que, a sua utilização já acontece há muitos anos e em vários países.

Segundo Gonçalves (2007), equoterapia é uma prática baseada em uma relação triangular e transferencialentre praticante-cavalo-terapeuta, dando ao praticante a possibilidade de vivenciar o mundo real e o seu imaginário. O cavalo desempenha a função de intermediário entre os dois mundos, o intrapsíquico do praticante, composto de angústias, desejos, e o externo, através de estímulos e da prática lúdica.

A partir da relação de troca entre cavalo e praticante, pode-se observar que a montaria propicia diversas alterações significativas no processo terapêutico.

De acordo com Walter e Vendramini(2000), o primeiro ajuste terapêutico do ser humano no cavalo é o ajuste tônico, uma vez que o animal nunca está imóvel, os seus movimentos como troca de apoio das patas, deslocamento da cabeça e os demais movimentos obrigam o praticante a se ajustar no seu comportamento muscular num movimento automático de adaptação.

SegundoQueiroz(2015a), aocaminharem"apasso" o corpo do praticante e do cavalo avançam para frente, inclinam lateralmente e também verticalmente subindo e descendo, formando o movimento tridimensional, tão importante na estimulação terapêutica.

$\mathrm{Na}$ equoterapia é possível a utilização de qualquer raça de cavalo. Háprioridades:sermanso, dócil esaudável, ser bem treinado e adestrado, ser bem preparado para não se assustar facilmente (commovimento brusco ou do praticante, com sons altos, ou mesmo com objetos que podem ser utilizados durante a prática).Há necessidade também de ter o cuidado para não trabalhar com a égua no período do cio e o cavalo deverá ser castrado. O que vai determinar a escolha do cavalo para o uso na prática da equoterapia é a marcha do animal, uma vez que essa produz um balanceio harmônico e se assemelha ao andar do homem (WALTER; VENDRAMINI, 2000).

Antes de iniciar as sessões é necessário observar o comportamento e a limpeza do cavalo, os equipamentos de montaria que serão utilizados, a vestimenta do praticante e a organização do local da prática (WALTER; VENDRAMINI, 2000).

Para o bom andamento da prática de equoterapia é necessário descrever a função da equipe que irá desempenhar a coordenação das atividades. Segundo Menezeset al.(2014), a equipe pode ser formada por profissionais das áreas de fisioterapia, psicologia, pedagogia, medicina veterinária, terapia ocupacional, fonoaudiologia, educação física e instrutor de equitação. A atuação desses profissionais na pista com o trabalho de reabilitação ocorre conforme o perfil clínico de cada praticante.

A Lei 13.830/19, no seu Art. $3^{\mathrm{a}}$, descreve os componentes para a formação da equipe multiprofissional:

I - equipe multiprofissional, constituída por uma equipe de apoio composta por médico e médico veterinário e uma equipe mínima de atendimento composta por psicólogo, fisioterapeuta e um profissional de equitação, podendo, de acordo com o objetivo do programa, ser integrada por outros profissionais, como pedagogo, fonoaudiólogo, terapeuta ocupacional e professores de educação física, que devem possuir curso específico de equoterapia;(BRASIL, 2019, p.4). 
Para Walter e Vendramini (2000), a equipe que vai trabalhar com o praticante, no picadeiro, deve contar com um cabo guia ou condutor e dois auxiliares laterais. $\mathrm{O}$ condutor pode ser qualquer técnico que faça parte da equipe e que tenha certo manejo com o animal, pois é ele quem vai dar comandos para o cavalo como o andar e o parar e também precisará estar atento para qualquer adversidade que possa vir a causar algum impacto negativo, assim atrapalhando o decorrer do tratamento. Os auxiliares laterais também são membros da equipe interdisciplinar e são os que fazem as intervenções necessárias de acordo com a potencialidade a ser trabalhada com o praticante durante o processo equoterápico.

O condutor, junto com os auxiliares laterais, no momento da prática, conversam com o praticante, vão interagindo com ele, propondo brincadeiras com a bola, argolas, cantando, elogiando, estimulando várias áreas físicas como levantar os braços, as pernas, ao mesmo tempo corrigindo a sua postura e promovendo a socialização e a melhoria da autoestima do praticante (GONÇALVES, 2007).

De acordo com Walter e Vendramini (2000), a prática também pode ser feita por montaria em dupla, isto é, uma pessoa da equipe monta junto ao praticante, que na maioria das vezes é um profissional de fisioterapia. Essa montaria é utilizada quando o praticante não tem o controle do tronco, assim não conseguindo ficar sentado sem o apoio nas costas.

$\mathrm{O}$ trabalho da equipe multiprofissional deve ser voltado para o crescimento biopsicossocial do praticante. Deve-se levar em conta a história de vida do praticante, como também todo o histórico familiar, de acordo com a anamnese, mas a ênfase deverá ser dada no que é observado em cada prática, fazendo o atendimento das dificuldades do praticante como um todo, proporcionando-lhe melhoras nos aspectos físicos e psíquicos. O trabalho deverá ser pautado no presente (QUEIROZ, 2015b).

$\mathrm{O}$ trabalho da equipe e familiares dever baseado num bom relacionamento e na harmonia, pois um bom clima entre os membros é fator fundamental para a aquisição de bons resultados. No decorrer do processo terapêutico, é importante que se estabeleça um vínculo de respeito, confiança recíproca e afeto entre os membros da equipe, o praticante, os familiares (GONÇALVES, 2007).

\section{Nosso centro e sua história}

De acordo com as entrevistas, no ano de 2006 a Prof $^{\mathrm{a}}$ Ivone Elizabeth Vander Mader começou a ministrar a disciplina optativa em Equoterapia, no Curso de Medicina Veterinária, na época Universidade
Severino Sombra. Essa disciplina teórica contemplava estágio prático utilizando o cavalo e uma equipe multiprofissional, iniciando o Projeto de Equoterapia.

Para que o projeto fosse estruturado em conformidade com as exigências legais a Prof ${ }^{a}$ Marcia Gabriel, Superintendente do Hospital e Gestora de Ensino convidou a Profa Juliana Fernandes de Souza Ribeiro, Psicóloga ea Prof ${ }^{a}$ Marcia Reis, Fisioterapeuta, para comporem a equipe multiprofissional e lhes foi oferecido pela Universidade, o Curso Básico de Equoterapia, ministrado pela ANDE-BRASIL, com a carga horária de 40h, em Juiz de Fora, M.G.

A Universidade fomentou, também, um Curso Básico de Equoterapia, que aconteceu na Casa Delta, em Ipiábas, Barra do Piraí, R.J., para alguns elementos da equipe. O Projeto contava com a participação de profissionais capacitados com curso específico de equoterapia e contava com estagiários dos cursos de Fisioterapia, Medicina Veterinária, Pedagogia e Psicologia.

A Prof ${ }^{a}$ Ivone convida o Prof. Thiago Luiz Pereira Marques, Médico Veterinário para fazer parte da equipe. Nessa época as práticas do Projeto aconteciam na Fazenda Experimental Método, no bairro do Ipiranga. Era um haras alugado pela Universidade.

$\mathrm{Na}$ Fazenda Experimental Método o cavalo utilizado era o Pombinho, animal muito querido pelos praticantes. Não havia sala lúdica, o picadeiro não era coberto, um complicador nos dias de chuva, pois atrapalhava o desenvolvimento dos trabalhos. Existia uma pista ampla para provas com cavalo de marcha e também mais atividades forado picadeiro onde eram explorados vários tipos de piso. Havia um piquete, que tinha um aclive e declive, algumas árvores que eram usadas ludicamente pelos praticantes e assim eles não enjoavam dos trabalhos. Naquele ambiente foram construídas atividades lúdicas: como a colocação de varal com algunsobjetos para queos praticantes pegassem. O funcionamento era multidisciplinar, com a participação de vários cursos.

No ano de 2008, a Prof ${ }^{\text {a }}$ Consuelo Mendes assume a Pró-Reitoria de Extensão e ao conhecer os resultados terapêuticos positivos obtidos por essa prática, e com a saída da Prof ${ }^{a}$ Ivone da instituição, desejou dar continuidade ao Projeto, ampliando-o, de modo que deixou de ser apenas um Projeto do Curso de Medicina Veterinária transformando-se em um Projeto de Extensão.

Em 2015, a prática deixou de acontecer na Fazenda Experimental Método e passou a ser desenvolvida na Unidade de Ensino Antonio Orlando Oslaine, rua Antenor Caravana, $n^{\circ}$ 921, bairro Carvalheira, Sítio do Barreiro, onde acontece até os dias de hoje, as sextasfeiras, no período letivo, no horário de $8 \mathrm{~h}$ às $12 \mathrm{~h}$.

Quando as práticas tiveram início no Sítio do Barreiro, elas aconteciam em um picadeiro aberto e 
aos poucos muitas melhorias foram sendo feitas: o fechamento do picadeiro com muro, a construção da cobertura para as práticas poderem acontecer mesmo nos dias de chuva, construção da rampa de acesso dos praticantes ao cavalo, construção da sala lúdica e aquisição de materiais lúdicos para serem trabalhados no picadeiro. Dessa forma, no Sítio do Barreiro há mais recursos para o trabalho.Podem ser propostas atividades envolvendo praticante e cavalo, fora do picadeiro,pensando no autocuidado a partir do cuidado com o animal como:rasqueá-lo, escová-lo e alimentálo.

Também no ano de 2015 a Prof Consuelo convidou a Prof $^{\mathrm{a}}$ Carolina de Lourdes Julião Vieira, Fisioterapeuta, para assumir a Coordenação do Projeto e em 2016 a Prof $^{a}$ Carolina vai a Brasília fazer o Curso Específico de Equoterapia promovido pela ANDEBRASIL. Em Brasília, a Prof ${ }^{a}$ Carolina verifica que o projeto desenvolvido na Universidade contemplava todos os requisitos exigidos para que o Projeto fizesse parte dessa associação. Assim no ano de 2017 o Projeto passou a ser agregado a Associação Nacional de Equoterapia, ANDE-BRASIL. Como Agregado a ANDE-BRASIL ele deixa de ser apenas um Projeto e é transformado em Centro de Equoterapia da Universidade de Vassouras, passando a ser reconhecido pela ANDEBRASIL.

Devido a demanda de novos atendimentos ser muito grande, a Universidade está pensando na possibilidade de oferecer mais um dia de atendimento. Para a viabilização desse aumento de gastos, a instituição está procurando parceiros,pois o Projeto é todo custeado pela Universidade.

Hoje, o Centro de Equoterapia da Universidade de Vassouras faz parte da Pró-Reitoria de Extensão Universitária e Desportos, tendo como Pró-Reitora a Prof ${ }^{a}$ Consuelo Mendes. É coordenado pela Prof ${ }^{a}$ Carolina de Lourdes Julião Vieira, Fisioterapeuta, e fazem parte da equipe o Prof. Thiago Luiz Pereira Marques, Médico Veterinário, e a Prof ${ }^{\mathrm{a}}$ Roberta Barbosa da Silva, Psicóloga. Conta também com a participação de alunos estagiários das áreas de Medicina Veterinária e Psicologia.

Hoje o Centro conta com três cavalos para a prática da equoterapia, a Malu, o Adamaceno e a Jangada. A escolha do animal utilizado varia de acordo com a necessidade do praticante, pois apesar de todos os animais serem dóceis, alguns exercem melhor função dependendo da atividade a ser feita, da patologia a ser trabalhada, como por exemplo, quando o praticante não tem controle da cervical é utilizadoum cavalo com a menor estatura para que os auxiliares possam dar melhor suporte (WALTER; VENDRAMINI, 2000).

A Malu é uma égua da cor pedrez, tem mais ou menos 18 anos, e não foi possível saber como chegou ao projeto. Ela aceita bem o trabalho com bolinhas, argola, bambolê e bastão. É usada quando a montaria é em duplae para exercício de equilíbrio.

O Adamaceno é um cavalo da cor castanha, tem mais ou menos 15 anos e chegou ao projeto há 4 anos. Ele aceita bem o trabalho com bolinhas, argola, bambolê e bastão. É usado para exercício de equilíbrio, volteio, passar por baixo, descer por trás e quando a montaria é individual. É o preferido dos praticantes devido a sua docilidade e imponência.

A Jangada é uma égua da cor tordilho, tem mais ou menos 15 anos e chegou ao projeto há 1 ano e meio. Ela aceita bem o trabalho com bolinhas e argola. É usada para exercício de equilíbrio e quando a montaria é individual.

Os cavalos são dóceis e fáceis de serem manejados. São treinados para não se assustarem na hora das atividades lúdicas no picadeiro, mesmo quando um praticante se aproxima ou quando jogam algum objeto neles.

O praticante pode escová-los, alimentá-los, e pode também passear pela área externa do sítio puxando-os, sempre acompanhado por três componentes da equipe, o condutor e dois auxiliares laterais.

\section{Análise dos impactos estatísticos do centro}

Através de pesquisa no arquivo do Centro de Equoterapia, foram encontradas noventa prontuários sendo que a maioria é do sexo masculino (com cinquenta e nove dos praticantes), totalizando $66 \%$ dos praticantes. Desses noventa praticantes, sessenta e um residem em Vassouras, sendo $71 \%$ do total. A idade deles varia entre 1 ano a 39 anos, sendo a faixa etária com maior número de praticantes é de 5 anos, com nove, sendo $10 \%$ dos mesmos. As patologias mais frequentes são o Comprometimento Motor com treze praticantes, sendo $41 \%$, o Transtorno do Espectro Autista com onze praticantes, sendo $34 \%$ e Síndrome de Down com oito praticantes, sendo $24 \%$.

Analisando a Figura 1, pode-se observar que a maior procura é para praticantes do sexo masculino. Dos noventa praticantes atendidos, cinquenta e nove são do sexo masculino, sendo $66 \%$ dos praticantes e trinta e um são do sexo feminino, sendo $34 \%$ dos praticantes.

Ao analisar a Figura 2 nota-se que a maioria dos praticantes que procuram o Centro residem em Vassouras e alguns residem em municípios circunvizinhos. Dos noventa praticantes atendidos, sessenta e um residem no município de Vassouras, perfazendo $71 \%$ deles, cinco praticantes são do município de Barra do Piraí e Valença, perfazendo $6 \%$, quatro praticantes são do município de Miguel Pereira, sendo 1\%, um praticante é do município de Engenheiro Paulo de Frontin, um de Paty de Alferes e um de Areal, sendo 1\% dos praticantes. 
Não havia identificação do município da residência nas fichas individuais de onze praticantes, perfazendo um total de $13 \%$.

$\mathrm{Na}$ pesquisa sobre as idades dos praticantes no início do tratamento, Figura 3 , percebe-se uma variação entre a idade de 1 ano a 39 anos. Foram seis praticantes que iniciaram a terapia com mais de 20 anos, $7 \%$ dos praticantes, vinte iniciaram o tratamento com a idade entre 10 a 19 anos, $22 \%$ dos praticantes, cinquenta e três iniciaram o tratamento com a idade entre 1 ano e 9 anos, sendo $59 \%$ dos praticantes e onze praticantes não foi identificado a idade, sendo $12 \%$. As idades mais procuradas para o atendimento variam entre 3 a 5 anos, sendo sete praticantes com 3 anos, oito com 4 anos e nove com 5 anos. Dessa forma, conclui-se que a maior procura é para praticantes com 5 anos, perfazendo $10 \%$ do total dos praticantes.

O Centro tem sido reconhecido como uma alternativa terapêutica para várias patologias. Ao analisar as fichas individuais foram encontradas as seguintes patologias: Transtorno do Espectro Autista, ComprometimentoCognitivo,ComprometimentoMotor,

Figura 1

\section{Residência dos Praticantes}

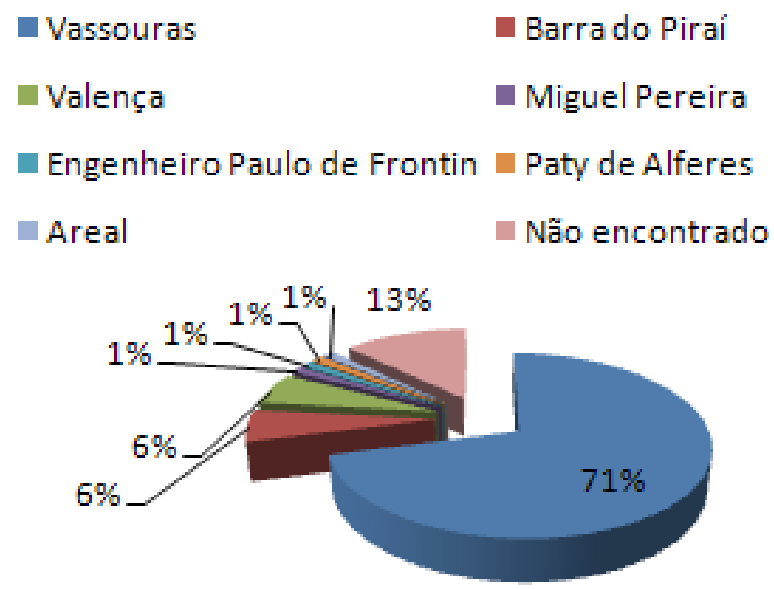

Figura 2

\section{Residência dos Praticantes}

\begin{tabular}{|c|c|}
\hline Vassouras & Barra do Piraí \\
\hline Valença & Miguel Pereira \\
\hline Engenheiro Paulo de Frontin & Paty de Alferes \\
\hline Areal & Não encontrado \\
\hline
\end{tabular}

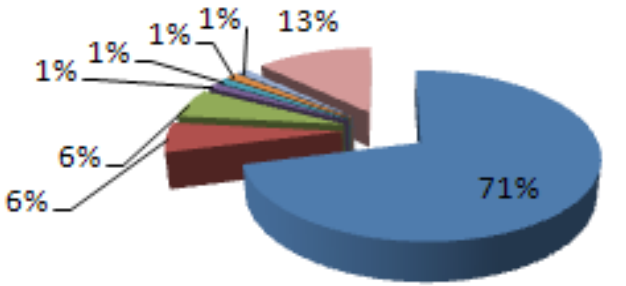


Figura 3

\title{
Idade de entrada
}

\author{
De 1 ano a 9 anos \\ De 10 anos a 19 anos \\ De 20 anos a 39 anos \\ - Não encontrado a idade
}
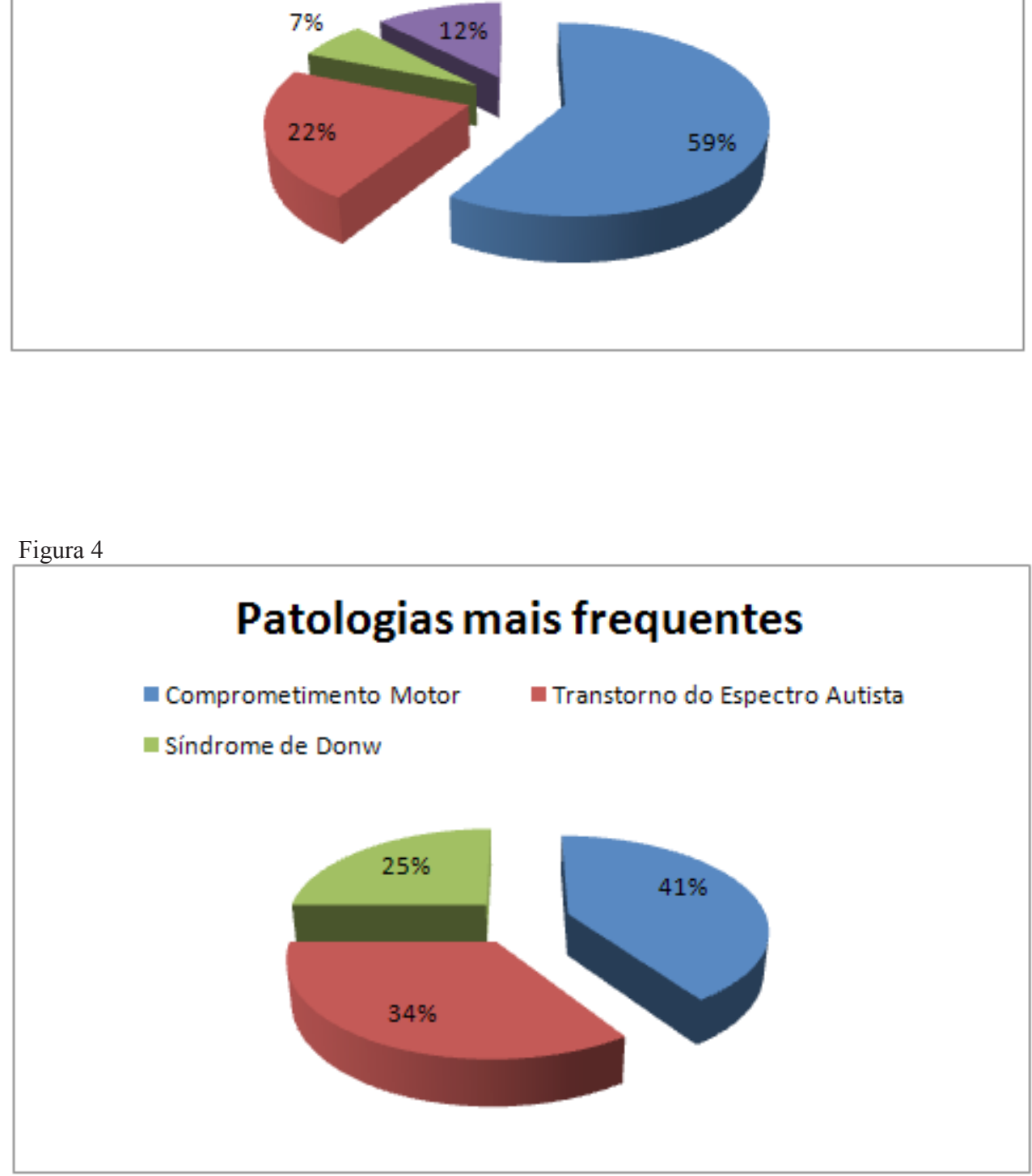

Depressão, Dislalia Severa, Dislexia, Encefalopatia, Esclerose Múltipla, Hidrocefalia, Hiperatividade, Microcefalia, Paralisia Cerebral, Síndrome de Angelman, Síndrome de Dandy-Walker, Síndrome de Down, Síndrome de Prader-Willi, Síndrome Kleefstra. As patologias mais frequentes, Figura 4, são o Comprometimento Motor emtreze praticantes, $41 \%$, o Transtorno do Espectro Autista em onze praticantes, $34 \%$ e Síndrome de Donw em oito praticantes, $24 \%$. Nota-se que a patologia com maior procura é para o comprometimento motor, com $41 \%$ dos praticantes.

Através de pesquisa bibliográfica foi levantado os benefícios da equoterapia para as patologias mais encontradas no Centro que são Comprometimento Motor, Transtorno do Espectro Autista e Síndrome de Down.

Para o Comprometimento Motor, muitos são os benefícios das atividades equoterápicas. Em Oliveira et al. (2014), encontramos que para praticantes com paralisia cerebral há ganhos motores e benefícios quanto a melhoria da simetria postural, do tônus muscular, melhora da função motora e mobilidade pélvica, contribuindo de modo significativo na reabilitação motora dos mesmos. 
Os benefícios da prática de equoterapia nas pessoas com Transtorno do Espectro Autista, TEA, podem ser observadas nas principais características apresentadas pelos portadores, que de acordo o Manual Diagnóstico e Estatístico de Transtornos Mentais, DSM V, APA (2014) são dificuldades na interação social, na comunicação social, déficit na reciprocidade socioemocional, redução de compartilhamento de interesse, afeto e emoção, anormalidade no contato visual, padrões restritos e repetitivos de comportamentos, estereotipias motoras, dentre outros.

Segundo Grubits Freire (2015), pode-se afirmar que a pessoa com Transtorno do Espectro Autista, ao participar da equoterapia pode superar as dificuldades de interação social, desenvolvimento emocional, motores, cognitivos e comportamentais. A equoterapia faz com que o praticante com essa patologia seja estimulado a entrar em outro ambiente, fora de sua rotina, com vários estímulos, possibilitando a melhoria na aprendizagem e tendo ganhono desenvolvimento cognitivo, e noesquema corporal. A melhoria das relações afetivas, emocionais e desenvolvimento da linguagem são os principais ganhos terapêuticos.

A síndrome de Down, segundo Dalla Dea e Duarte (2009), que é a presença de um cromossoma a mais no par 21, passando a ter 47 cromossomos, acarreta um desequilíbrio genético, alterando a cognição, o desenvolvimento e a maturação do organismo.

Os benefícios da equoterapiapodem ser comprovados através de estudos feitos por Chaves e Almeida (2018) que apontam importantes ganhos motores como equilíbrio estático e dinâmico, reflexos tendinosos profundos, melhoria do tônus, força muscular, controle das sinergias globais e motricidade fina. Ganhos neuropsicológicos como melhor organização espacial e capacidade de orientação, esquema corporal, aumento dos tempos de atenção e maior capacidade de expressão e linguagem, ações com mais independência, autonomia, segurança, canalização da agressividade, respeitando os limites impostos pelo cavalo, melhoria na aprendizagem e mudanças positivas na socialização e no perfil de personalidade. A equoterapia produz resultados eficazes para praticantes com síndrome de Down.

\section{Análise dos impactos biopsicossociais do centro}

Com base na análise do conteúdo das entrevistas, Anexo I, com profissionais que trabalharam e trabalham na equoterapia conclui-se que os resultados do Projeto sempre foram muito bons. Através das avaliações individuais dos praticantes é possível verificar os benefícios nos aspectos motores, melhora do equilíbrio, desenvolvimento da autonomia, melhoria na autoestima,mudança da forma de ver o mundo,por estar sobre um cavalo, (a partir de uma visão mais alta), melhora da qualidade das relações intrapessoais e sociais, desenvolvimento da capacidade de esperar, que para alguns praticantes é um pouco insuportável.

Como o trabalho é desenvolvido por uma equipe multiprofissional, é possível desenvolver os aspectosbiopsicossoiais dos praticantes, procurando beneficiá-lo para além da prática em cima do cavalo, para além da prática da equoterapia.

Nas entrevistas compais, ou responsáveis de praticantes do Centro, Anexo II, os benefícios gerados para aqueles que frequentam a Equoterapia são: melhora na disciplina, na capacidade de esperar a sua vez,no equilíbrio corporal, socialização, coordenação motora, percepção espacial, comunicação oral e equilíbrio emocional. Enfatizando a melhora nos aspectos motores como sustentação do pescoço, da sustentação do tronco, possibilidade de andar, possibilidade de correr para quem não andava, e andar de bicicleta. Destaca-se a interação e o amor ao cavalo.

Poucos foram asdificuldades geradas, porém três entrevistados relataram o receio do praticante em ter contato com o animal e um citou o medo de altura. Vale ressaltar que uma das respostas foi a necessidade ter mais dias de atividade.

Em relação a pergunta sobre a necessidade de complementar com informação relevante, alguns dos responsáveis demonstram gratidão pela existência do projeto, ressaltandoa paciência, o cuidado, dedicação e amor da equipe para com os seus filhos. Reconhecem a importância da equoterapia na melhoria física e mental dos praticantes. Uma dos responsáveis sugeriu que seria importante ter mais divulgação para a comunidade, para que mais pessoas pudessem ter acesso.

Com base na análise das respostas, pode-se observar que os pontos citados pelos pais ou responsáveis são extremamente positivos, mostrando assim a eficácia da Equoterapia.

\section{Considerações Finais}

O Centro de Equoterapia da Pró-Reitoria de Extensão da Universidade de Vassouras desenvolve um trabalho terapêutico, educacional e social, de forma multidisciplinar, utilizando o cavalo, para praticantes que apresentam dificuldades motoras e/ou problemas de saúde mental. É um atendimento filantrópico, que acontece há 13 anos, sendo reconhecido positivamente não só na comunidade de Vassouras como também em cidades circunvizinhas.

Nestes 13 anos o Centro atendeu 90 praticantes. Desses 59 praticantes são do sexo masculino, 61 residem em Vassouras, e a idade com maior número de praticantes é de 5 anos. As patologias mais frequentes 
são o Comprometimento Motor, Transtorno do Espectro Autistae Síndrome de Down.

As atividades terapêuticas desenvolvidas são reconhecidas por sua excelência nos resultados, tanto por profissionais que atuaram ou ainda atuam no Centro, como também pelos pais ou responsáveis dos praticantes.

O Centro de Equoterapia vem contribuindo para a melhoria da qualidade de vida dos praticantes e consequentemente a melhoria da qualidade das relações familiares, como também proporcionando aos alunos a oportunidade de fazerem estágio diferenciado contribuindo para uma formação ampliada e enriquecimento dos seus currículos.

Através dos dados colhidos e da articulação teórica foi possível perceber que a Universidade de Vassouras,através do Centro de Equoterapia, vem contribuindo positivamente para a comunidade de Vassouras e cidades circunvizinhas uma vez que possibilita, ao praticante, o autoconhecimento, melhoria da autoestima, da socialização, proporciona a oportunidade de lidar com sentimentos e emoções e faz emergir suas potencias físicas e emocionais. E principalmente auxilia na ressignificação da subjetivação e na redução de danos para a saúde mental do praticante.

\section{Referências}

AMERICAN PSYCHIATRIC ASSOCIATION (APA). Manual diagnóstico e estatístico de transtornos mentais. 5. ed. Porto Alegre : Artmed, 2014. Disponível em: https:/www.tdahmente.com/wp-content/uploads/2018/08/ Manual-Diagn \%C3\%B3stico-e-Estat\%C3\%ADstico-de-TranstornosMentais-DSM-5.pdf Acesso em: 05 fev 2019.

ASSOCIAÇÃO NACIONAL DE EQUOTERAPIA.Brasília:ANDE BRASIL,2019. Disponível em:http://equoterapia.org.br/articles/index/ article_detail/142/2022.

Acesso em: 14 set 2018

BARDIN, L. Análise de conteúdo.Lisboa: Edições 70, 2000.

BRASIL, Lei n ${ }^{\circ} 13.830$, de 13 de maio de 2019. Dispõe sobre a prática da equoterapia. Diário Oficial da União: seção 1, nº 91, p .4, Brasília, DF, ano 2019. Disponível em: http://pesquisa.in.gov.br/imprensa/jsp/visualiza/index. jsp? jornal $=515 \&$ pagina $=4 \&$ data $=14 / 05 / 2019$. Acesso em: 28 maio 2019.

CHAVES L.O.; ALMEIDA R.J. Os benefícios da equoterapia em crianças com Síndrome de Down.Revista Brasileira Ciência e Movimento - UCB. n. 26.2. Brasília, 2018. Disponível em: https://portalrevistas.ucb.br/index.php/ RBCM/article/viewFile/6873/pdf. Acesso em: 21 mar 2019.

DALLA DÉA, V. H. S.; DUARTE, E.Síndrome de Down. Informações, caminhos e histórias de amor. Phorte editora. São Paulo, 2009.

GRUBITS FREIRE, H. B. Estudo de Caso: Equoterapia com uma Criança Portadora de Distúrbio Autista Atípico.Programa de Equoterapia da Universidade Católica Dom Bosco. PROEQUO-UCDB. Campo Grande, MS2015. Disponível em: http://equoterapia.org.br/media/artigosacademicos/documentos/18091716.pdf. Acesso em: 22 maio 2019.

GONCALVES, R. H. R. Equoterapia e psicologia: um estudo sobre o papel do psicólogo nessa prática. Universidade Paulista- UNIP ICH. 2007. Disponível em: http://equoterapia.org.br/media/artigos-academicos/ documentos/25031143.pdf. Acesso em 21 mar 19.

MENEZES, D. B.; SILVÉRIO, J. R.; COSTA, L. S.; PEREIRA, R. B. S.; TAKEDA, S. G. A. A. Y F. A Atuação do Psicólogo na Equoterapia:
Um Estudo de Caso. Psicologado.ed. 04, 2014. Disponível em: https:// psicologado.com.br/atuacao/psicologia-da-saude/a-atuacao-do-psicologona-equoterapia-um-estudo-de-caso. Acesso em: 14 mar 2019.

OLIVEIRA, M. P. F. O,; SANTOS, R. F; OLIVEIRA, V. M. M. O Efeito da Equoterapia no Tratamento da Paralisia Cerebral: Revisão de Literatura. Fundação Universitária Vida Cristã, Pindamonhangaba, São Paulo, 2014. Disponível em: http://www.bibliotecadigital.funvicpinda.org.br:8080/jspui/ bitstream/123456789/257/1/OliveiraSantosOliveira.pdf. Acesso em: 15 maio 2019.

QUEIROZ, C. O. V. Visualização da semelhança entre os movimentos tridimensionais do andar do cavalo com o andar humano. ANDE BRASIL. 2015. Disponível em: http://equoterapia.org.br/media/artigos-academicos/ documentos/20082221.pdf. Acesso em: 27set 2018.

Família Interagindo com a Equipe Interdisciplinar de Equoterapia.ANDE_BRASIL. 2015. Disponível em: http://equoterapia. org.br/submit forms/index/miid/192/a/dd/did/5610. Acesso em: 27 set 2018 .

WALTER, G. B; VENDRAMINI, O. M.Equoterapia - Terapia com o uso do cavalo. Centro de Produções Técnicas/CEE-Universidade Federal de Viçosa - MG, 2000 
Anexo I

Entrevista com Profissionais que trabalharam na implantação do Centro de Equoterapia da Universidade de Vassouras

1- $\quad$ Em qual ano o Centro de Equoterapia da Universidade de Vassouras começou as suas atividades?

2- $\quad$ Em qual endereço?

3- $\quad$ O que você sabe sobre a história da fundação do Centro?

4- $\quad$ Relate um pouco sobre como acontecia a prática da terapia.

5- $\quad$ Deseja complementar com alguma informação relevante à pesquisa?

Anexo II

Entrevista com Pais de Praticantes do Centro de Equoterapia da Universidade de Vassouras

1- Há quanto tempo seu(sua) filho(a) pratica Equoterapia no Centro de Equoterapia da Universidade de Vassouras?

2- Quais benefícios foram gerados depois da prática em equoterapia?

3- Quais dificuldades foram geradas pela prática da equoterapia?

4- $\quad$ Deseja complementar com alguma informação relevante a pesquisa? 